Europe's Journal of Psychology, 7(2), pp. 534-549

www.ejop.org

\title{
Role of arousal states in susceptibility to accept misinformation
}

\author{
Ari Sudan Tiwari \\ Defence Institute of Psychological Research, Delhi, India
}

\begin{abstract}
The fragile nature of eyewitness memory makes the witnesses susceptible to various sources of post event information. Many factors of individual differences further moderate the impact of misinformation. The experiment reported here attempts to explore the effects of post event information on recognition accuracy of witnessed events, as moderated by the arousal states of energetic arousal, tense arousal, hedonic tone and anger/frustration. Experiment used those participants who scored high on four arousal states and average on rest of the three arousal states. Participants viewed a video clip, depicting a murder, followed by presentation of one week delayed post event information and recognition test for details of the event. Results indicated that participants who were misled retained less number of details of the event than did the participants who were given either consistent or no post event information. High scorer energetic arousal and hedonic tone participants retained more details of the event than did the high scorer tense arousal and anger/frustration participants under all the three post event information conditions. However, high tense arousal and anger/frustration participants' eyewitness retention dropped more sharply when they were given misleading post event information in comparison to the high energetic arousal and hedonic tone participants. Thus, results of the study indicated a moderating effect of post event information by the arousal states.
\end{abstract}

Keywords: arousal states, eyewitness accuracy, misinformation effect, post event information.

People occasionally encounter with some highly emotional events like brutal murder, robbery, sexual molestation, etc. They accordingly register, encode and store these details and reproduce or recognize them when required to do so. The accuracy of recall of witnessed event is the extent to which people reproduce or recognize these 
details perfectly. Some of the details, which are often required to be reproduced or recognized, are the contents, people, objects, actions and processes of the event. As an organism endures any unexpected sequence of disturbing and heart-rending situation he becomes emotionally so over-charged that he apart from being stunned also undergoes a state of stupefaction. Howsoever disturbing such an event might be to a person, he finds it very difficult to testify for legal procedures the exact sequence of happenings at a later point of time. The confusion becomes worse confounded by the addition of further inputs from the media and other sources.

Several laboratory studies support the view that memory for details of emotionally arousing events is less accurate than memory for details of neutral events (Morgan, Hazlett, Doran, Garrett, Hoyt, Thomas, Barnoski, \& Southwick, 2004; Stark, Okado, \& Loftus, 2010; Valentine, \& Mesout, 2009). Past researches on eyewitness testimony (e. g., Belli, 1989; Gupta, \& Sondhi, 2009; Loftus, Donders, Hoffman, \& Schooler, 1989; Saunders, \& MacLeod, 2002) have repeatedly demonstrated that misleading post event information may negatively impact the accuracy of eyewitness memory of participants. In one of such studies, Loftus and Loftus (1975) showed their research participants a film of a traffic accident and then two groups of participants were asked slightly different questions. One of the groups was asked: "How fast were the cars going when they hit each other?" The other group was asked: "How fast were the cars going when they smashed into each other?" In a one week delayed retention test the participants were asked whether they had seen any broken glass in the film resulting from the accident. Although there had not been any, the second group distinctly remembered having seen the broken glass scattered about the road. Apparently, the words of the question had cued their expectations.

This phenomenon is known as "suggestibility" or "misinformation effect" for which Loftus and her co-workers (Loftus et al., 1989) have proposed 'memory impairment hypothesis'. This hypothesis states that misleading post event information alters a person's memory for original episode by somehow 'erasing' or 'overwriting' the original memory trace. It asserts that the destructive updating of original memory trace results in systematic and predictable deficits in performance on subsequent tests (see Loftus, 2005, for a review of the misinformation effect).

The memory impairment hypothesis was challenged by McCloskey and Zaragoza (1985) who advanced the 'co-existence hypothesis', which assumes that the original memory trace is unaffected by post event information. The two researchers used an alternate procedure to test eyewitness accuracy, termed as the modified test procedure, in which the misleading information was not included in the option on the test and argued that for a number of reasons (such as demand characteristics) 
subjects might select the misleading item even if they still remembered the original one. An alternative explanation for suggestibility effect, proposed by Bowers and Bekarian (1984) is known as the 'accessibility hypothesis', which asserts that misleading information decreases the accessibility of the original memory. Study with matched encoding and retrieval contexts by Bowers and Bekarian (1984) extended support to this hypothesis as the magnitude of misleading information was found decreased.

Lindsay (1990) proposed a different explanation called 'the source misattribution hypothesis'. This hypothesis assumes that the post event information does not actually impair memory for original event; it actually creates confusion about the sources of the two-information. Lindsay (1990) found that in the high source discriminability conditions subjects did not report suggested details more often on misled items than they did on control items, while in the low discriminability conditions subjects experienced genuine source monitoring failures when they claimed that they had seen the suggested details in the slides.

Many factors of individual differences further moderate the impact of misinformation (see Gallo, 2006, for a review). In a recent study many personality characteristics were found to interact with cognitive abilities to moderate susceptibility to misinformation (Zhu, Chen, Loftus, Lin, He, Chen, Li, Moyzis, Lessard, \& Dong, 2010). The researchers found that low cognitive abilities, being associated with personality characteristics of low fear of negative evaluation, low harm avoidance, high cooperativeness, high reward dependence, and high self-directedness, enhanced susceptibility to the misinformation effect. Studies have also been conducted to associate certain cortical activities with misinformation effect (Stark, Okado, \& Loftus, 2010). Study indicated that since sensory modalities of original and misinformation were different, they produced different brain activation patterns for the two sources of information. H. J. Eysenck $(1957,1967)$ explained the personality dimensions of extraversion-introversion based on differential arousability of cortico-reticular circuit, which includes the cerebral cortex, the thalamus and the ascending reticular activating system. He thought that this system is more readily aroused in introverts than in extraverts, so that introverts are more easily aroused and show higher level of cortical arousal. This differential arousability is believed to influence many observable behaviours and performance of persons holding one of the either personality dimensions on various types of tasks, including eyewitness memory accuracy in different ways.

It is argued that emotional arousal causes attentional narrowing, i.e., a decrease in the range of cues an individual can attend to, resulting in a poorer memory for 
peripheral aspects of an emotional event. This attentional narrowing results in enhancement of memory for the central facts of the event. Although emotion can affect memory (e.g., Hever \& Reisberg, 1990), not everyone appears to experience emotion to the same intensity. Larsen, Diener, \& Cropanzano (1987) examined differences in cognitive processes during exposure to emotionally relevant stimuli accounted by affect intensity of the individuals. They reported that high affect intensity subjects reported more physical sensations and more emotional arousal in response to emotional slides (positive and negative) than they did to the neutral slides. High affect intensity subjects employed more personalizing, generalizing, and empathic cognitions and global and elaborate thinking. These results supported the idea that individuals predisposed to have strong emotional responses also had the tendency to deploy different type of cognitive processes when exposed to emotional stimuli than low affect intensity individuals. Larsen, Billings, \& Cutler (1996) examined individual differences in cognitive interpretation of emotional situations in terms of active information generation. They reported that the subjects high in affect intensity generated descriptive information containing significantly more references to emotional arousal, more focus on feelings and more overgeneralization compared to the subjects low in affect intensity. Thus, specific cognitive processing could be associated with dispositional affect intensity and that people's informational style is stable over time and across situations.

Researches on attention and judgment have shown that discrete emotions lead to enhanced attention to, and accessibility of, motivationally relevant information (Williams, Mathews, \& McLeod, 1996). Fearful people have been found to preferentially attend to threat related information (Loewenstein, Weber, Hsee, \& Welch, 2001; Ohman, Flykt, \& Esteves, 2001) and interpret ambiguous situations as threatening (M. W. Eysenck, 1997). Fearful individuals flaunt enhanced memory for threat related information and poorer memory for threat irrelevant details (Wessel \& Merckelbach, 1998). Enhanced memory for threatening stimuli has also been demonstrated in the framework of eyewitness research. The notion of weapon focus has been proposed to illustrate this phenomenon which refers to witnesses' tendency to attend and remember the weapon used in the event and ignoring other fringe information (e.g., Kramer, Buckhout, \& Eugenio, 1990; Loftus, Loftus, \& Messo, 1987).

Thus, it is evident that the dimensions of arousal have differential cognitive implications (Matthews, Pitcaithly, \& Mann, 1995; Matthews, \& Westerman, 1994; Mayer, Salovey, Gomberg-Kaufman, \& Blainey, 1991). These cognitive implications have been largely investigated with low and high affect intensity individuals and to have a comprehensive understanding of the process a broader comparison is 
required. Arousal, emotion and mood are inter-linked states (Matthews, \& Deary, 1998) and the Activation-Deactivation Adjective Checklist developed by Thayer (1978) assesses two dimensions of subjective arousal, referred to as energetic arousal and tense arousal. Energetic arousal is characterized by the dimensions of vigour and energy on one side, and tiredness and fatigue on the other. Tense arousal contrasts tension and nervousness with relaxation and calmness. Matthews, Jones and Chamberlain (1990) added a third dimension of hedonic tone related to the overall pleasantness of mood. Anger as a dimension of arousal has also been extensively researched and has been reported as a psychological predictor of chronically elevated blood pressure (Spielberger, Jacobs, Russell, \& Crane, 1983). Psychometric evidences indicate that extraversion is related positively with energetic arousal and hedonic tone, while it is negatively related with tense arousal.

An evaluation of researches discussed here steer to believe that a threatening event depicting a violent sequence would be retained differentially by the individuals of different arousal states. Therefore, in the present experiment effects of four arousal states (energetic arousal, tense arousal, hedonic tone and anger/frustration) and eyewitness retention scores of participants under three types of post event information conditions (consistent, misleading and no information) has been studied. At the outset, it is hypothesised that high tense arousal and anger/frustration participants would be more susceptible to accept misinformation than those high on energetic arousal and hedonic tone.

Method

Participants

120 extreme scorers on the Hindi adaptation of UWIST Mood State Adjective Checklist (Mathews, Dwivedi, A.P. Singh, Srivastava, Arora, \& I. L. Singh, 1995), aged 18 to 25 years ( $M=22$ years and 7 months), were used as participants in this experiment. Those extreme scorers on each of the four arousal states of the UMS were selected on the basis of the statistic of $M+.6745 \sigma$ who scored average on the rest of the three arousal states. Thus, high scoring energetic arousal, tense arousal, hedonic tone, and anger/frustration participants formed the four groups for the experiment. Each of three post event information conditions comprised forty participants who were drawn in equal number from each of the four arousal states described above. Thus, each of the four groups was purely represented by high scorer participants on one the four arousal states. It was believed that such a design 
could enable to make better comparison of susceptibility to accept misinformation among the arousal states.

Materials

Hindi adaptation of UWIST Mood State Adjective Checklist (Mathews, Dwivedi, A.P. Singh, Srivastava, Arora, \& I. L. Singh, 1995) was used to select high scoring energetic arousal, tense arousal, hedonic tone, and anger/frustration participants. The UMS consisted of 29 adjectives to be rated on four point scales. There were eight items each for energetic arousal, tense arousal and hedonic tone mood states and five items for anger/frustration mood state. One could obtain maximum score of 32 (with minimum of 8) on energetic arousal, tense arousal and hedonic tone mood state scales and a maximum score of 20 on anger/frustration mood state scale with a minimum of 5 . Coefficients of internal consistency for the subscales were .87 for energetic arousal, .82 for tense arousal, .89 for hedonic tone, and .79 for anger/frustration.

The to-be-witnessed event in the experiment was a video clip of 3 minutes and 15 seconds duration. The event centred around two friends who had met after a long gap. During their conversation they begin quarrelling over some issue. Meanwhile, two persons come and one of them shoots one of the two friends.

Two types of post event information were given through two versions of the narrative. The consistent post event information condition correctly described the event and items given in the test. On the other hand, the narrative of misleading post event information condition employed some misleading cues about the event. There was another group, which was given neither of the two versions of narratives.

A retention test comprising 20 items regarding details of the event was constructed. The details which were required to recognize were the contents, people, objects, actions and processes of the event. Each test item was in the question form regarding some aspect of the event with three alternatives. One of the alternatives was the correct one, which really appeared in the event and also in the narrative of consistent post event information condition. The other two alternatives were incorrect; one of which was suggestive, as it did not appear in the event but it did find a mention in the narrative of misleading post event information condition. The third alternative appeared neither in the event nor in the misleading narrative. For example, there was an item: "How the two friends met to each other at first time in the event?" Three alternatives to it were: (a) By saying 'Namaskar' (b) By rubbing their shoulders (c) By shaking their hands. This particular part of the event was 
narrated in the consistent post event information condition in these words: "The two friends met in a room by rubbing their shoulders" while, in the misleading post event information condition, it was explained in this way: "The two friends met in a room by shaking their hands."

Items of the test were selected in such a way that all relevant details of the event were well covered. Difficulty level of the test items was also checked carefully in a preliminary try-out and equal proportion of mild, moderate and high difficulty level items were included in the final test. For scoring, one score was awarded for each correct answer with no credit to the incorrect answer.

Procedure

The reported study was undertaken at the Department of Psychology, Banaras Hindu University, Varanasi, India which used a video clip depicting an event of murder. The event, as well as the complete experimental procedure, was reviewed by the Departmental Research Committee (DRC) which subsequently granted permission to use it as witness event. As per the directions of the DRC, participants of the study were a priori informed about emotional content of the event at the time of taking their consent of participation in the study.

The experiment was conducted in 3 phases.

Phase 1: In this phase, participants were exposed to the witnessed event via a video recorded clip, as described above.

Phase 2: One week later, participants were given either of the two types of post event information, consistent or misleading, through written narratives in such a way that each type of post event information was supplied to one third of the participants. The participants of no post event information condition did not undergo this phase of the study; in other words they received neither consistent nor misleading post event information. Participants were instructed that the narrative was a written explanation of that event.

Phase 3: Just after their reading of the narrative, participants' memory about the witnessed event was tested through a recognition test that contained 20 items. The participants in the no post event information condition received this phase without undergoing Phase 2. Instructions given to the research participants before the retention test was: "Last week, a short video film was presented before you. Here, some questions are given related to the incidents of that film. Each question has 
three alternatives in the questionnaire. Select one of them on the basis of the actual incidents occurred in the film and mark $(\sqrt{ })$ before the true answer." Thus, they were clearly instructed to report about the details of the original event viewed one week before.

Experimental Design

The design of this experiment was a 3 (consistent, misleading and no post event information) $\times 4$ (energetic arousal, tense arousal, hedonic tone, and anger / frustration participants) between subjects factorial design with ten participants in each of the 12 experimental conditions.

\section{Results}

Table 1 shows that misleading post event information resulted in the lowest retention score $(M=8.00, S D=3.28)$ in comparison to consistent $(M=15.73, S D=1.70)$ or no post event information $(M=10.23, S D=2.48)$. The main effect for post event information was significant, $F(2,108)=404.66, p<.0001$ (Table 2). This is also evident that high energetic arousal $(M=14.00, S D=2.48)$ and hedonic tone $(M=12.63, S D=3.67)$ participants retained more event details than the high tense arousal ( $M=9.00, S D=4.60)$ and anger/frustration $(M=9.63, S D=3.74)$ participants. There was statistically significant main effect of arousal states, $F(3,108)=110.04, p<.0001$.

Table 1: Mean eyewitness retention scores and SDs of high scorers on different arousal states as a function of post event information

\begin{tabular}{|c|c|c|c|c|c|c|c|c|}
\hline \multirow[b]{3}{*}{ Arousal states } & \multicolumn{8}{|c|}{ Post event information } \\
\hline & \multicolumn{2}{|c|}{ Consistent } & \multicolumn{2}{|c|}{ Misleading } & \multicolumn{2}{|c|}{ No } & \multicolumn{2}{|c|}{ Overall } \\
\hline & Mean & SD & Mean & SD & Mean & SD & Mean & SD \\
\hline Energetic arousal & 17.00 & 1.15 & 11.90 & 1.29 & 13.10 & 1.00 & 14.00 & 2.48 \\
\hline Tense arousal & 14.90 & 1.20 & 4.50 & 1.27 & 7.50 & 1.18 & 9.00 & 4.60 \\
\hline Hedonic tone & 16.90 & 1.10 & 9.80 & 1.48 & 11.20 & 1.32 & 12.63 & 3.67 \\
\hline Anger/Frustration & 14.10 & 1.20 & 5.70 & 1.16 & 9.10 & 1.60 & 9.63 & 3.74 \\
\hline Overall & 15.73 & 1.70 & 8.00 & 3.28 & 10.23 & 2.48 & 11.31 & 4.14 \\
\hline
\end{tabular}

Table 1 further shows that apart from performing poor with consistent and no post event information, high tense arousal $(M=4.50, S D=1.27)$ and anger/frustration $(M=5.70, S D=1.16)$ participants' eyewitness retention scores dropped more sharply when they were given misleading post event information in comparison to the high energetic arousal $(M=11.90, S D=1.29)$ and hedonic tone $(M=9.80, S D=1.48)$ 
participants (Figure 1). Interaction between arousal states and types of post event information was also found significant, $F(6,108)=8.90, p<.0001$.

Table 2: Summary of ANOVA for eyewitness retention scores

\begin{tabular}{lrrrrr}
\hline Source of variance & Sum of squares & \multicolumn{1}{c}{ df } & Mean square & \multicolumn{1}{c}{$F$} & \multicolumn{1}{c}{ Sig. } \\
\hline PEI & 1271.667 & 2 & 635.833 & 404.655 & .000 \\
Arousal States & 518.692 & 3 & 172.897 & 110.035 & .000 \\
PEI X Arousal States & 83.533 & 6 & 13.922 & 8.860 & .000 \\
Error & 169.700 & 108 & 1.571 & & \\
Total & 17389.000 & 120 & & & \\
\hline
\end{tabular}

Figure 1: Mean eyewitness retention scores of high scorers on different arousal states as a function of post event information

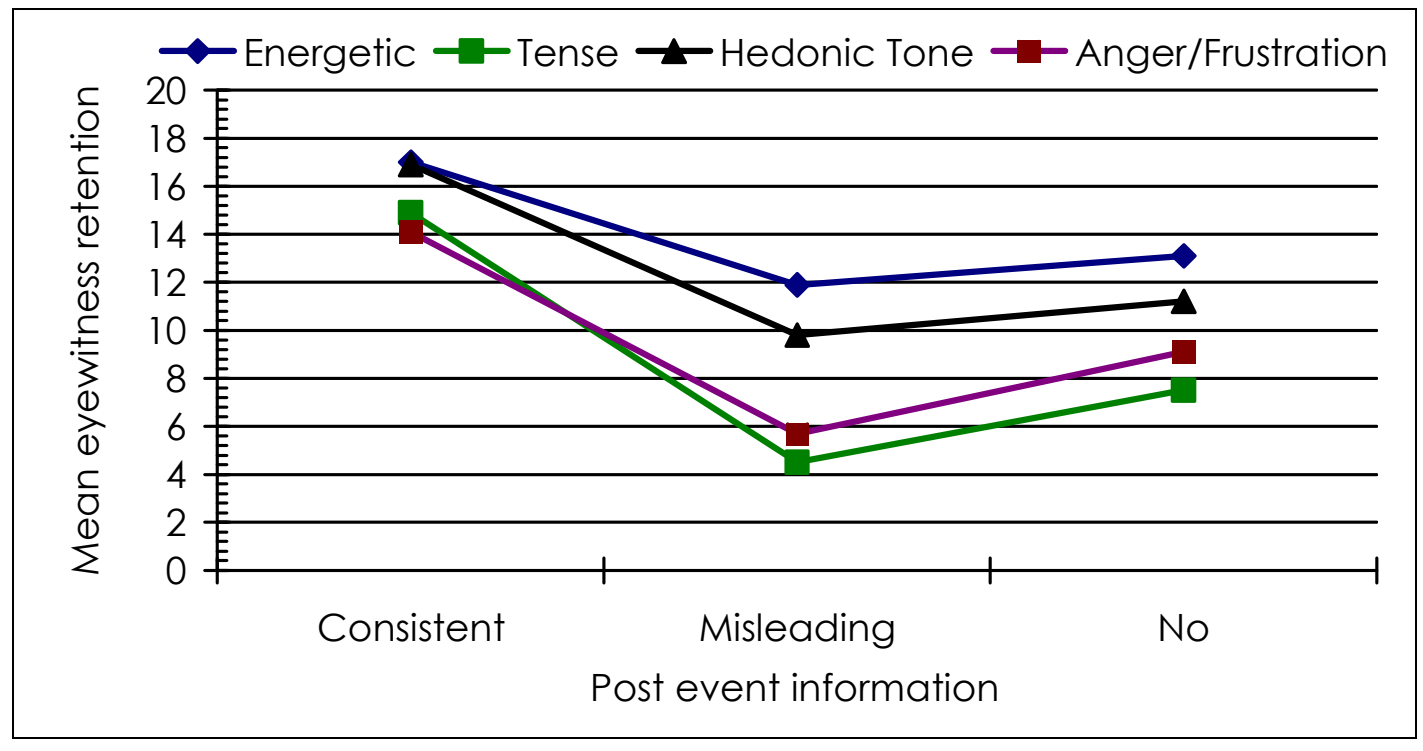

Tukey's h.s.d. post-hoc comparisons of eyewitness accuracy among various levels of post event information (Table 3 ) revealed that the mean retention score of the participants receiving consistent information was significantly greater than that of the participants receiving misleading $(p<.000)$ and no $(p<.000)$ information. However, misled participants obtained significantly lesser eyewitness details than did the participants of no information group $(p<.000)$. Comparisons among various levels of arousal states indicated that high energetic arousal participants retained significantly more eyewitness details than high tense arousal $(p<.000)$, hedonic tone $(p<.000)$ and anger/frustration $(p<.000)$ participants. Similarly, high hedonic tone participants retained significantly more eyewitness details than did the high anger/frustration participants $(p=<.000)$. High tense arousal participants recognized significantly lesser eyewitness details than did the high hedonic tone participants $(p<.000)$. 
Table 3: Post hoc multiple comparisons (Tukey's h. s. d. test) of eyewitness accuracy among various levels of arousal states and post event information

\begin{tabular}{llrl}
\hline \multirow{2}{*}{\multicolumn{1}{c}{$J$}} & Mean differences (I- & \multirow{2}{*}{ Sig. } \\
\hline Post event information & & & \\
\hline Consistent & Misleading & $7.75^{*}$ & .000 \\
& No & $5.50^{*}$ & .000 \\
Misleading & No & $-2.25^{*}$ & .000 \\
\hline Arousal states & & & .000 \\
\hline Energetic arousal & Tense arousal & $5.03^{*}$ & .000 \\
& Hedonic tone & $1.37^{*}$ & .000 \\
Tense arousal & Anger/frustration & $4.37^{*}$ & .000 \\
& Hedonic tone & $-3.67^{*}$ & .173 \\
Hedonic tone & Anger/frustration & -.67 & .000 \\
\hline
\end{tabular}

\section{Discussion}

Results extend the theory that consistent post event information enhances the traces by the phenomenon of priming. Since both the misled and the no information groups did not get supportive information, there was no priming or enhancement of memory traces. The results lend support to memory impairment hypothesis inasmuch as the misleading post event information presumably erases memory of the original event. There is a rewriting of the event as described in the post event information. Consistent post event information further strengthens memory of the original event. However, when neither of the two post event information was given, participants' memory was neither erased nor strengthened. As a result the retention of the no post event information group remained unaltered.

The effect of post event information on retention extends the theory of misinformation acceptance and deliberation (see Belli, 1989 and Loftus et al., 1989 for details). Results show that the participants receiving no and misleading post event information accessed the original memory equally well. On the occasions when participants did not receive any post event information failed to remember the original item, they guessed the correct alternative on the basis of probability. However, misled participants remembered both the original and misled items and responded with the misled item because they trusted the experimenter's information than they did their own memory. They apparently performed less accurately than did the no post event information participants who never received any post event information and for whom such demand characteristics were not present also. 
Results of the present experiment show statistically significant effect of participants' arousal states on their eyewitness memory scores. Correlations among UWIST Mood Adjective checklist scores and measures of Curran and Cattell's (1974) Eight State Questionnaire (8 SQ) have shown that participants high on energetic arousal and hedonic tone were significantly low scorers on the 8 SQ scales of anxiety, stress and fatigue while, they were high scorers on extraversion (Matthews, 1987). A contrary pattern of correlations was found for the scores on tense arousal. Vigour-energy and tiredness-fatigue have been reported as key traits of energetic arousal, while tension-nervousness and relaxation-calmness have been shown to be key traits of tense arousal (Thayer, 1978). In a subsequent study, Thayer (1989) related energetic arousal to a general appetite or action system, whereas tension has been associated with a preparatory-emergency system, which is particularly sensitive to cognitive appraisals of danger stimuli. Here it is important to point out that the witnessed event employed in the present study depicted a violence sequence ending in a murder. The witnessed event in all likelihood resembled to a somewhat threatening stimulus, which presumably triggered a preparatory-emergency situation. The trend of results in the present study extends support to Thayer (1989).

Differing explanations for anxiety related processing and attentional biases have been advanced. Processing stage theory of Williams, Watts, MacLeod and Mathews (1988) suggests that anxiety affects processing and causes highly selective attention with automatic and unconscious encoding. M. W. Eysenck's (1992) hyper-vigilance theory argues that trait anxious participants, particularly when high in state anxiety, tend to scan the environment for threat to an excessive degree. When a threat is detected, they tend to 'lock on to' the threat stimulus and their focus of attention is narrowed. Wells and Matthews (1994) have identified emotional distress with a cognitive-attentional syndrome generated by a 'Self-Referent Executive Function'. High trait anxious individual's attentional functioning is characterized by self-focused attention and his processing effort is diverted to worry and ruminative emotionfocused coping. The syndrome includes the activation of strategies for allocation of attention, which prioritises processing of threat-related stimuli and the person monitors the threats congruent with his personal concerns.

The processes of focused, narrowed and selective attention discussed in the theories stated above adequately explain the results of the present experiment where the participants with different levels in the traits of anxiety, tension, stress, energy, vigour and fatigue were found to account their differential memory accuracy. Participants who scored high on the scale of tense arousal were presumably higher in their traits of anxiety and stress and the event used in the present study further raised their state anxiety, which resulted in extreme level of focussing and narrowing of their attention. 
The view of 'weapon focusing' also assumes that while witnessing a violent event attention is focused on the weapon and other details of the event are ignored or overlooked. This phenomenon of weapon focusing becomes prevalent in high trait anxious participants. They attained and encoded such threatening stimuli with their personal concerns, but only on the expense of other details which resulted in their lower eyewitness memory accuracy (Hulse, \& Memon, 2006).

On the contrary, high energetic arousal and hedonic tone participants were presumably low on trait anxiety and high in energy. Therefore, no such narrowing and focusing of attention occurred in them, which resulted in their better eyewitness memory accuracy. Energy has been reported to be associated with enhanced performance on a range of attentionally demanding tasks (Mathews \& Westerman, 1994). Energetically aroused participants paid adequate attention to the entire range of stimuli present in the event and therefore, participant's scores on the memory test were significantly higher than that of the high tense aroused and anger/frustration participants.

Results of the experiment reported here unequivocally support the view that misleading post event information impairs the memory for details of an emotional event and susceptibility to accept the misinformation also varies across the four arousal states of the research participants. However, the study was conducted in the laboratory situation, while eyewitness accounts pertain to the naturalistic settings. The duration of the event was also very little, while in actual scenario the events take considerably longer time. In addition to high scorer participants for the four arousal states, the experimental treatments could also be expanded by selecting low scorer participants for a comprehensive comparison among the four arousal states. In addition to the subjective arousal, measurement of physiological arousal of the participants could be taken to comprehensively decipher the role of arousal in susceptibility to accept misinformation. Finally, participants used in this experiment were of a particular age group (early adults) and therefore, any generalization about others becomes difficult. It is suggested that further studies steering clear of these limitations may be planned to better understand the complex nature of eyewitness memory.

\section{References}

Belli, R. F. (1989). Influences of misleading postevent information: Misinformation interference and acceptance. Journal of Experimental Psychology: General, 118, 72-85. 
Bowers, J. M., \& Bekerian, D. A. (1984). When will postevent information distort eyewitness testimony? Journal of Applied Psychology, 69, 466-479.

Curran, J. P., \& Cattell, R. B. (1974). The Eight State Questionnaire. Champaign II; IPAT.

Eysenck, H. J. (1957). The dynamics of anxiety and hysteria. London: Routledge and Kegan Paul.

Eysenck, H. J. (1967). The biological basis of personality. Springfield, III: Thomas.

Eysenck, M. W. (1992). Anxiety: the cognitive perspective. Hillsdale, NJ: Erlbaum.

Eysenck, M. W. (1997). Anxiety and cognition: A unified theory. Hove, England: Psychology Press.

Gallo, D. A. (2006). Associative illusions of memory: False memory research in DRM and related tasks. New York: Psychology Press.

Gupta, A., \& Sondhi, V. (2009). Eyewitness memory and investigating interviewing. In A. Begum (Ed.). Eyewitness identification: Psych-legal issues. The Icfai University Press. pp.110-133.

Hever, F., \& Reisberg, D. (1990). Vivid memories of emotional events. The accuracy of remembered minutiae. Memory \& Cognition, 18, 496-506.

Hulse, L., \& Memon, A. (2006). Fatal iampact? The effects of emotional arousal and weapon presence on police offecers' memories for a simulated crime. Legal \& Criminological Psychology, 11, 313-325.

Kramer, T. H., Buckhout, R., \& Eugenio, P. (1990). Weapon focus, arousal, and eyewitness memory: Attention must be paid. Law and Human Behavior, 14, 167-184.

Larsen, R. J., Billings, D. W., \& Cutler, S. E. (1996). Affect intensity and individual differences in information style. Journal of Personality, 64, 185-207.

Larsen, R. J., Diener, E., \& Cropanzano, R. S. (1987). Cognitive operations associated with individual differences in affect intensity. Journal of Personality and Social Psychology, 53, 767-774. 
Lindsay, D.S. (1990). Misleading suggestions can impair eyewitnesses' ability to remember event details. Journal of Experimental Psychology: Learning, Memory, and Cognition, 16, 1077-1083.

Loewenstein, G. F., Weber, E., Hsee, C. K., \& Welch, N. (2001). Risk as feelings. Psychological Bulletin, 127, 267-286.

Loftus, E. F. (2005). Planting misinformation in the human mind: A 30-year investigation of the malleability of memory. Learning and Memory, 12, 361-366.

Loftus, E. F., Donders, K., Hoffman, H., \& Schooler, J. W. (1989). Creating new memories that are quickly accessed and confidently held. Memory \& Cognition, 17, 607-616.

Loftus, E.F., \& Loftus, G.R. (1975). Leading questions and the eyewitness report. Cognitive Psychology, 7, 560-572.

Loftus, E.F., Loftus, G.R., \& Mesoo, J. (1987). Some facts about "weapon focus". Law and Human Behavior, 11, 55-62.

Matthews, G. (1987). Personality and multidimensional arousal: A study of two dimensions of extraversion. Personality and Individual Differences, 8, 9-16.

Matthews, G., \& Deary, I. J.(1998). Personality Traits. Cambridge University Press.

Mathews, G., Dwivedi, C. B., Singh, A. P., Srivastava, A. K., Arora, M., \& Singh, I. L. (1995). Hindi adaptation of UWIST Mood State Adjective Checklist. Department of Psychology, B. H. U.: Varanasi.

Matthews, G., Jones, D. M., \& Chamberlain, A. G. (1990). Refining the measurement of mood: the UWIST Mood Adjective Checklist. British Journal of Psychology, 81, 17-42.

Matthews, G., Pitcaithly, D., \& Mann, R. L. E. (1995). Mood, neuroticism and the encoding of affective words. Cognitive Therapy and Research, 19, 563-87.

Matthews, G., \& Westerman, S. J. (1994). Energey and tension as predictors of controlled visual and memory search. Personality and Individual Differences, 17, 617-626.

Mayer, J. D., Salovey, P., Gomberg-Kaufman, S., \& Blainey, K. (1991). A broader conception of mood experience. Journal of Personality and Social Psychology, 60, 100 111. 
McCloskey, M., \& Zaragoza, M. (1985). Misleading postevent information and memory for events: Arguments and evidence against memory impairment hypothesis. Journal of Experimental Psychology: General, 114, 1-16.

Morgan, C. A., Hazlett, G., Doran, A., Garrett, S., Hoyt, G., Thomas, P., Barnoski, M., \& Southwick, S. M. (2004). Accuracy of eyewitness memory for persons encountered during exposure to highly intense stress. International Journal of Law and Psychiatry, 27, 265-279.

Ohman, A., Flykt, A., \& Esteves, F. (2001). Emotion drives attention: Detecting the snake in the grass. Journal of Experimental Psychology: General, 130, 466-478.

Saunders, J., \& MacLeod, M. D. (2002). New evidence on the suggestibility of memory: The role of retrieval-induced forgetting in misinformation effects. Journal of Experimental Psychology: Applied, 8, 127-142.

Spielberger, C. D., Jacobs, G. E., Russell, S., \& Crane, R.S. (1983). The assessment of anger: the State-trait anger scale. In J.N. Butcher and C.D. Spielberger (eds.) Advancement in personlaity assessment, 2, Hillsdale, NJ: Erlbaum, pp. 259-285.

Stark, C. E. L., Okado, Y., \& Loftus, E. F. (2010). Imaging the reconstruction of true and false memories using sensory reactivation and the misinformation paradigms. Learning and Memory, 17, 485-488.

Thayer, R. E. (1978). Toward a psychological theory of multidimensional activation (arousal). Motivation and Emotion, 2, 1-34.

Thayer, R. E. (1989). The biopsychology of mood and arousal. Oxford University Press.

Valentine, T., \& Mesout, J. (2009). Eyewitness identification under stress in the London Dungeon. Applied Cognitive Psychology, 23, 151-161.

Wells, A., \& Matthews, G. (1994). Arousal and emotion: a critical perspective. Hove: Lawrence Erlbaum.

Wessel, I., \& Merckelbach, H. (1998). Memory for threat-relevant and threat-irrelevant cues in spider phobics. Cognition and Emotion, 12, 93-104.

Williams, J. M. G., Mathews, A., \& Macleod, C. (1996). The emotional stroop task and psychopathology. Psychological Bulletin, 120, 3-24. 
Williams, J. M. G., Watts, F. N., MacLeod, C., \& Mathews, A. (1988). Cognitive psychology and emotional disorder. Chichester: Wiley.

Zhu, B., Chen, C., Loftus, E. F., Lin, C., He, Q., Chen, C., Li, H., Moyzis, R. K., Lessard, J., \& Dong, Q. (2010). Individual differences in false memory from misinformation: Personality characteristics and their interactions with cognitive abilities. Personality and Individual Differences, 48, 889-894.

\section{About the author:}

Ari Sudan Tiwari, Ph. D., is working as a Scientist at Defence Institute of Psychological Research, DRDO, Delhi, India. His areas of interests are eyewitness testimony, emotionmood-arousal and memory, and meta-cognitive processes. He is presently working in the field of group dynamics and leadership, human and organizational cognition, and psycho-physiological impact of sleep deprivation.

Address for correspondence: Ari Sudan Tiwari, Defence Institute of Psychological Research, Defence Research \& Development Organization, Lucknow Road, Timarpur, Delhi-1 10054 (INDIA).

Email: arisudantiwari@gmail.com 